\title{
Multidisciplinary Outpatient Cancer Rehabilitation Can Improve Cancer Patients' Physical and Psychosocial Status-a Systematic Review
}

\author{
Daisy Kudre $^{1} \cdot$ Zhehui Chen $^{1} \cdot$ Aline Richard $^{1} \cdot$ Sophie Cabaset $^{1} \cdot$ Anna Dehler $^{1} \cdot$ Margareta Schmid $^{1}$. \\ Sabine Rohrmann ${ }^{1}$ (D)
}

Accepted: 7 September 2020 / Published online: 1 October 2020

(C) The Author(s) 2020

\begin{abstract}
Purpose of Review This systematic review aimed to determine the effects of interdisciplinary/multidisciplinary outpatient rehabilitation programmes by looking at physical, psychosocial and return to work status of adult cancer patients.

Recent Findings There is growing evidence that emphasizes the importance of interdisciplinary/multidisciplinary rehabilitation especially in outpatient care, which addresses the complex and individual needs of cancer patients. Many studies focus on measuring the effect of individual rehabilitation interventions.

Summary Randomized controlled trials (RCTs) and before-after studies examining the effects of interdisciplinary/multidisciplinary outpatient rehabilitation programmes were included in this systematic review. The electronic literature search was conducted in MEDLINE, EMBASE, CINAHL, Cochrane Central Register of Controlled Trials and PEDro. The PICO statement was used for selection of the studies. Six randomized controlled trials and six before-after studies were included. Interdisciplinary/multidisciplinary outpatient cancer rehabilitation programmes improved physical and/or psychosocial status of cancer patients. However, non-significant changes in a variety of single physical and psychosocial measures were also common.

The findings of the systematic review indicate that interdisciplinary/multidisciplinary outpatient cancer rehabilitation can improve cancer patients' physical and psychosocial status. This review is limited by the narrative approach due to the heterogeneity of outcome measures. To evaluate effects of rehabilitation, better comparable studies are necessary. Further research is needed in regard to long-term outcomes, effects on return to work status and on the associations depending on cancer type.
\end{abstract}

Keywords Cancer rehabilitation · Outpatient rehabilitation · Multidisciplinary rehabilitation $\cdot$ Systematic review

\section{Introduction}

The number of people living with a cancer diagnosis is constantly increasing due to an aging population and successful cancer treatment. Thus, cancer is progressively seen as a chronic disease [1]. However, cancer itself and its treatment

This article is part of the Topical Collection on Integrative Care

Daisy Kudre and Zhehui Chen are co-first authors

Sabine Rohrmann

sabine.rohrmann@uzh.ch

1 Division of Chronic Disease Epidemiology; Epidemiology, Biostatistics and Prevention Institute, University of Zurich, Hirschengraben 82, CH-8001 Zurich, Switzerland can result in a wide range of physical and psychological impairments, e.g. pain, fatigue, cognitive difficulties, anxiety and depression, having a negative effect on cancer patients' quality of life (QoL) [2].

Cancer rehabilitation has been proven effective in decreasing the side effects of cancer and cancer treatment. WHO has defined rehabilitation as a "set of interventions designed to optimize functioning and reduce disability in individuals with health conditions in interaction with their environment" [3]. Studies mostly focus on measuring the effect of individual rehabilitation interventions after cancer diagnosis or treatment, such as physical activity [4]. For example, it was observed in a meta-analysis that physical activity interventions helped reduce cancerrelated fatigue and anxiety and increased the functional QoL as well as aerobic fitness and muscle strength [5]. 
Psychological interventions also reduced fatigue [6] and anxiety [7]. Interventions such as consultation with an occupational physician supported cancer survivors in returning to the workplace [8].

However, growing evidence emphasizes the importance of interdisciplinary and multidisciplinary rehabilitation, which addresses the complex needs of cancer patients through a more comprehensive approach compared with monodisciplinary care [9-11]. Interdisciplinary rehabilitation is defined as a programme where several health care specialists agree on mutual goals while working on these goals in individual sessions. Regular meetings and coordinated information flow are an integral part of such programmes. Multidisciplinary rehabilitation, in contrast, does not necessarily include synergic teamwork [12].

To the best of our knowledge, two systematic reviews have been conducted on the effects of inpatient and outpatient cancer rehabilitation, but they observed mixed effects $[13,14]$. Scott et al. examined the effects of multidimensional, i.e. often monotherapy that focused on at least two interventional aspects (e.g. counselling to foster physical activity and better stress management), but not necessarily multidisciplinary interventions [14•]. Mewes et al. focused also on multidimensional intervention and included also multidisciplinary interventions [13•]. Thus, there is still a lack of knowledge concerning rehabilitation that is truly multidisciplinary, not only multidimensional. Furthermore, little is known about the effects on physical and psychosocial health particularly for outpatient cancer rehabilitation, which refers to rehabilitation that is offered at a hospital or medical facility without being admitted. Such outpatient programmes can be longer than inpatient programmes, but are usually less intensive.

The aim of the study was to review the characteristics of interdisciplinary/multidisciplinary outpatient rehabilitation programmes in research published so far and to assess the effects of rehabilitation programmes for physical, psychosocial and/or return to work status of adult cancer patients. Both interdisciplinary rehabilitation and multidisciplinary rehabilitation were included and are referred to as 'multidisciplinary' in this study. To the best of our knowledge, this is the first systematic review to assess the effects of multidisciplinary outpatient cancer rehabilitation (MOCR). Studies with an inpatient or a multidimensional setting were not included.

\section{Material and Methods}

\section{Search Strategies}

Electronic databases for the literature search included MEDLINE, EMBASE, CINAHL, Cochrane Central
Register of Controlled Trials and PEDro. The search was performed on June 19, 2018. Search terms focused on cancer and interdisciplinary or multidisciplinary rehabilitation and were used in combinations and adaptions for each electronic database, according to the expertise of a librarian. Randomized controlled trials (RCTs), as well as quantitative study types, were included due to little available research in the field of MOCR, thus providing the potential to supplement RCT evidence.

\section{Study Selection}

The PICO statement was used to set criteria for considering studies for this review.

Only studies with adult cancer patients ( $\geq 18$ years old), with any cancer type and stage, were included (Population). Studies with multidisciplinary/interdisciplinary outpatient cancer rehabilitation, which were defined as conducting two or more Interventions, were included if they have been delivered during or up to 2 years after the end of the primary treatment. Controls were not specified. Outcomes assessed the physical and/or psychosocial effectiveness and/or the return to work status.

Two reviewers independently assessed titles and abstracts of the retrieved articles, categorizing them into 'inclusion criteria fulfilled [A]', 'inclusion criteria not fulfilled [B]' or 'unclear [C]'. Inclusion criteria consisted of four aspects: diagnosis of cancer, rehabilitation, study design and cancer patients being adult. The decisions of the two reviewers were compared and articles rated as [A-A] or $[\mathrm{A}-\mathrm{C}]$ were included for full-text screening. For combinations of $[\mathrm{A}-\mathrm{B}]$, further evaluations followed to decide whether to include the article or not. Then, two reviewers independently evaluated full texts of all potentially eligible papers. Briefly, the inclusion criteria of the full-text screening consisted of the minimum of two different interventions of which one, but not both, included physical training. Further inclusion criteria were the timeframe of rehabilitation in an outpatient setting (during or up to 2 years after the end of cancer treatment), the quantitative study design (RCTs or before-after studies) and the use of at least one assessment tool before and during or at the end of the rehabilitation. Additionally, disagreements and unclear decisions were resolved by consensus.

\section{Data Extraction and Risk of Bias}

The data was independently extracted from the two review authors using a predeveloped data extraction template which covered general aspects (e.g. authors, title), methods, participants, interventions and outcome.

The Cochrane Collaboration's risk of bias tool [15] was used to assess the risk of bias resulting from random sequence 
generation (selection bias), allocation concealment (selection bias), blinding of participants and personnel (performance bias), blinding of outcome assessment (detection bias), incomplete outcome data (attrition bias), selective reporting (reporting bias) and bias due to confounding in each study. If no conclusion about a bias could be drawn due to the nature of the study (e.g. blinding of participants in either receiving or not receiving rehabilitation interventions), or the study design (e.g. random sequence generation in non-randomized trials), the entry was judged with 'high risk of bias'. Bias due to confounding was added to the original Cochrane tool of bias list to evaluate further bias in non-randomized studies.

This systematic review was registered in PROSPERO (CRD42018100145).

\section{Results}

\section{Study Selection}

Database searching resulted in 7763 articles, and after removing duplicates, 4465 articles were screened by title and abstract. Two hundred ninety articles were considered for full-text screening. Finally, 12 articles were included for the systematic review (Fig. 1).

Fig. 1 Workflow of the systematic review

\section{Study Characteristics}

Five of the studies included were carried out in Denmark [16-19], two in the USA [20, 21], and one each in South Korea [22], Australia [23], Belgium [24], the Netherlands [25] and Norway [26]. Out of 12 studies included, six were randomized controlled trials [16-18, 20-22], two were controlled before-after studies $[23,24]$ and four were uncontrolled before-after studies [19, 25-27]. In the following text, RCTs and before-after studies were analyzed separately due to the differences in methodological quality and level of evidence.

\section{Randomized Controlled Trials}

Detailed information is listed in Table 1. In summary, the sample size of the six RCTs varied from 65 [22] to 269 cancer patients [16] resulting in a total of 862 participants. Four of the RCTs $[16,18,20,21]$ included participants with different types of cancer.

In four RCTs, MOCR was provided for cancer patients still undergoing chemotherapy and/or radiation therapy $[16,17$, 20, 21]. MOCR programmes all included physical training and some type of psychological counselling interventions, partly also relaxation methods. They lasted from 2 to 4 weeks [21] to 12 months [18], and the intensity varied from $1.5 \mathrm{~h}$ per week [18] to $9 \mathrm{~h}$ per week [16]. Cancer patients allocated to

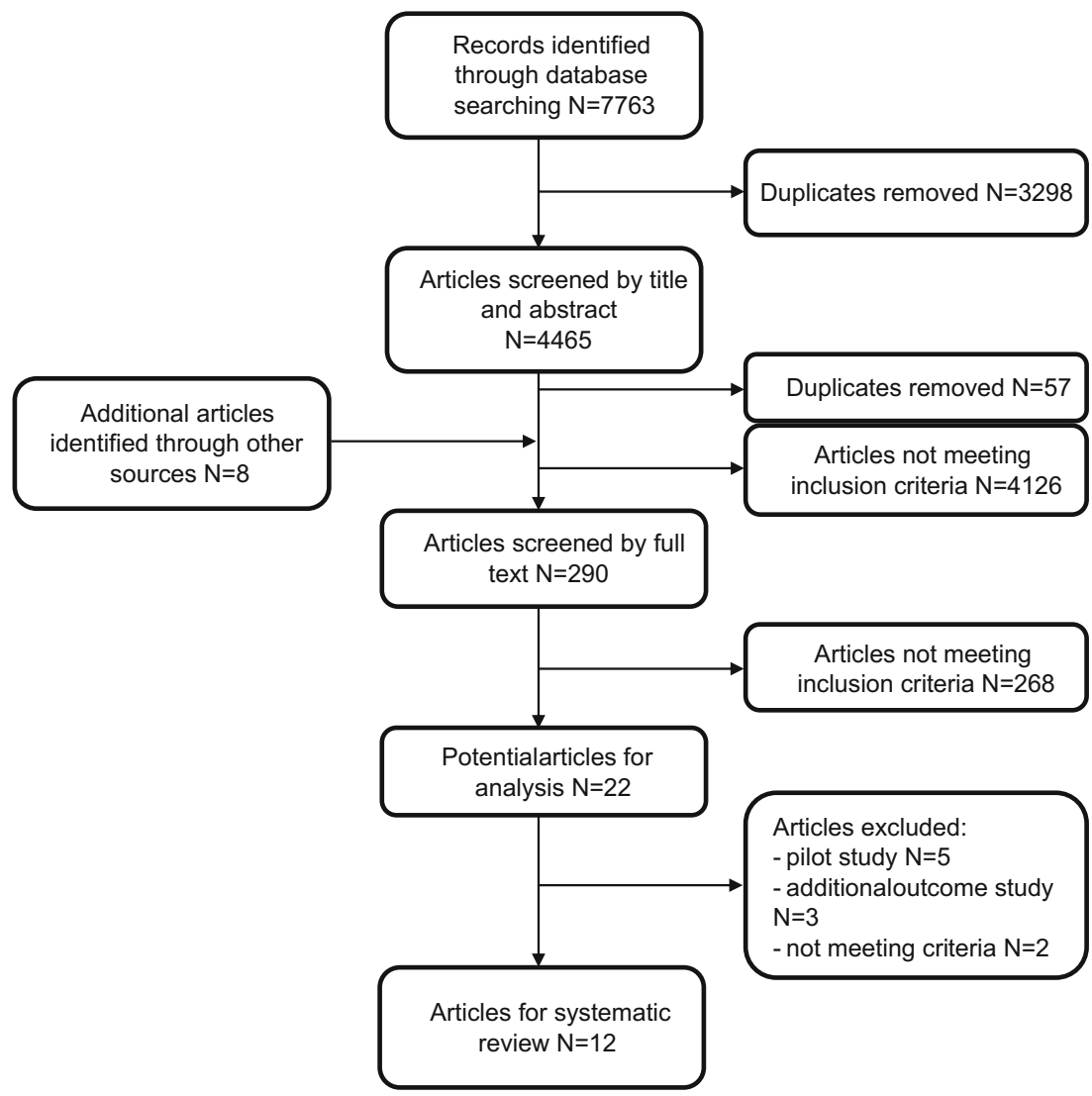




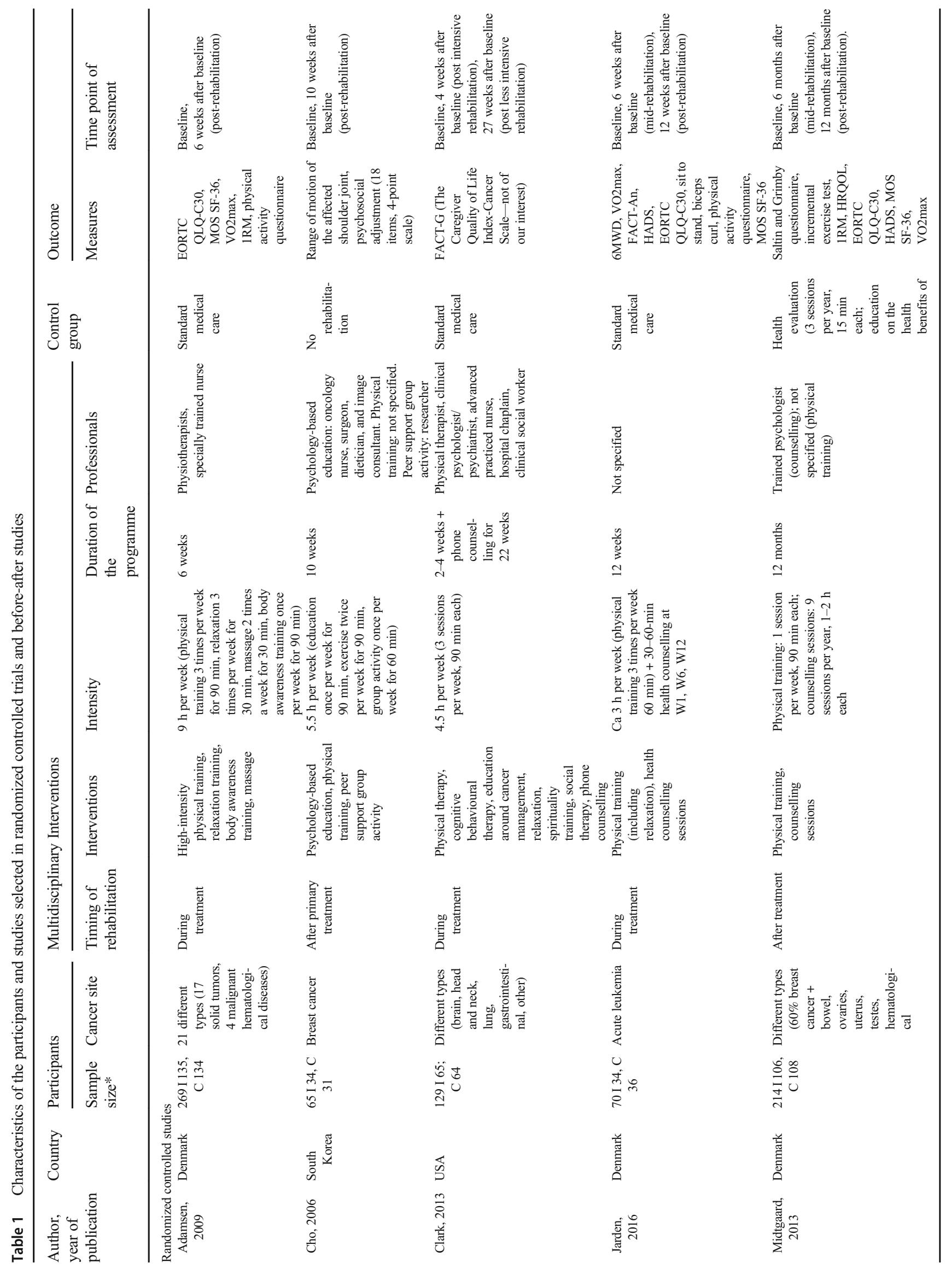




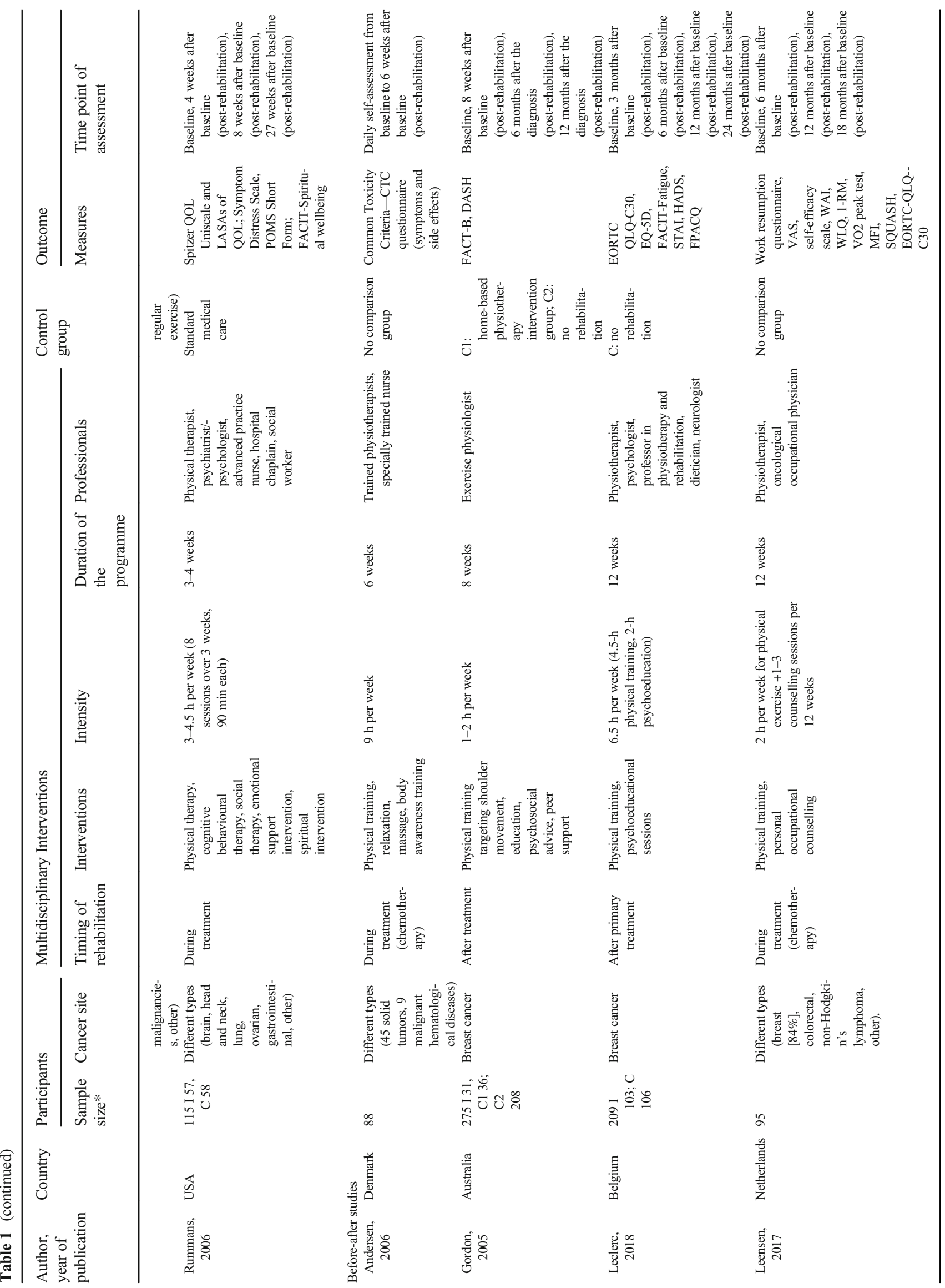




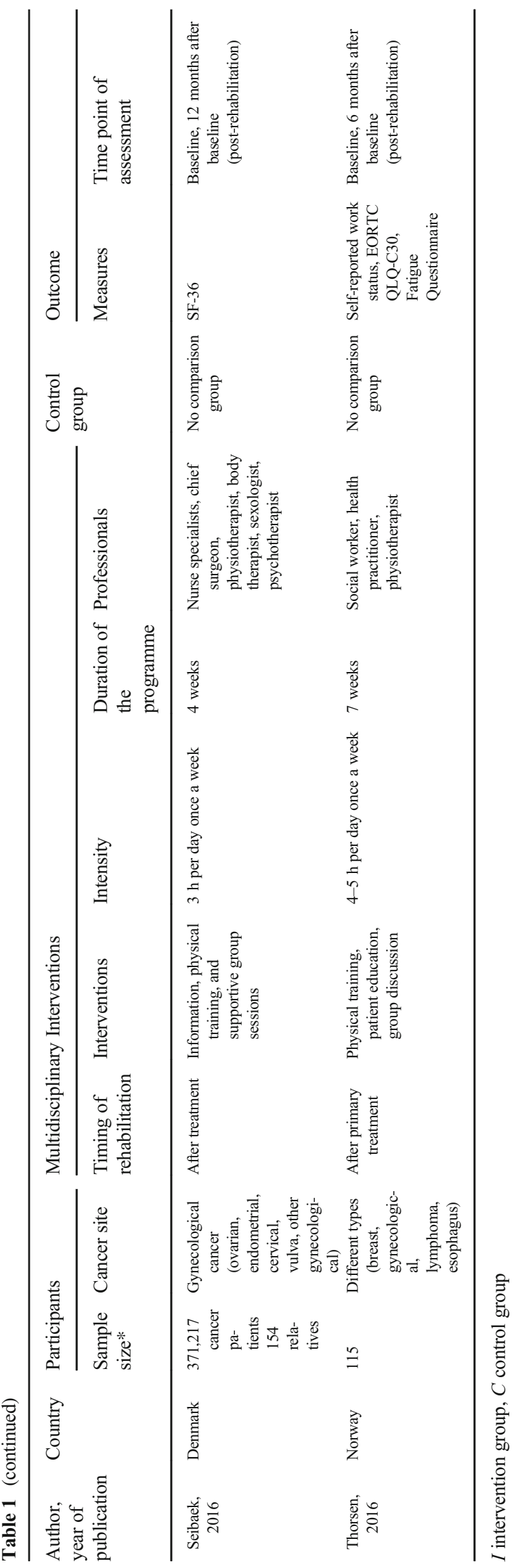

the control group received standard medical care only, except for one study, in which a less intense intervention was applied [18].

\section{Before-After Studies}

The sample size of studies included varied from 88 [27] to 275 cancer patients [23], and the total sample size for the six before-after studies was 1153 participants. Three studies [25-27] included participants with different types of cancer, two studies [23, 24] included breast cancer patients and one study [19] patients diagnosed with a gynecological cancer.

In two studies [25, 27], the rehabilitation programme included cancer patients undergoing chemotherapy; in the other 4 studies [19, 23, 24, 26], rehabilitation was provided after completion of (primary) treatment. MOCR programmes in before-after studies included physical training as well as some type of psychological counselling. They lasted 4 [19] to 12 weeks $[24,25]$ with an intensity ranging from 1 to $2 \mathrm{~h}$ per week [23] to $9 \mathrm{~h}$ per week [27]. One study included two control groups receiving either home-based physiotherapy interventions or no rehabilitation [23] and the other before-after study with a control group applied no rehabilitation to the controls (Table 1) [24].

\section{Outcome Assessment}

The most commonly used outcome measurements among the six included RCTs were the QoL of cancer patient's questionnaire (EORTC QLQ-C30) and the Medical Outcomes Study 36-Item Short Form Survey Instrument (MOS SF-36), both used in three RCTs [16-18]. In addition, three RCTs [17, 20, 21] used one or more subscales of Functional Assessment of Chronic Illness Therapy (FACIT); another three [16-18] measured cardiorespiratory fitness via $\mathrm{VO} 2 \mathrm{max} /$ peak test. Others used less known QoL questionnaires or psychosocial adjustment scales [22]. Similarly, in before-after studies, the most commonly used outcome measure was EORTC QLQ-C30 in three [24-26], a subscale of FACIT in two [23, 24] and return to work status in another two studies $[25,26]$ (Table 1).

Outcomes were assessed at various time points. In all RCTs, assessments were done at baseline and directly after the end of the rehabilitation (Fig. 2a). Only one study [21] assessed the outcome of rehabilitation not only after the intervention, but also approximately 4 and 23 weeks after the end of the intervention. In before-after studies, three studies [23, 24] assessed outcomes at baseline and directly after the end of the rehabilitation. Except for one study [27], all before-after studies measured outcomes also some time after the end of rehabilitation, between 6 weeks and 24 months after baseline (Fig. 2.b). 
Fig. 2 a Duration of multidisciplinary rehabilitation and time point of outcome assessment in RCTs. b Duration of multidisciplinary rehabilitation and time point of outcome assessment in before-after studies a

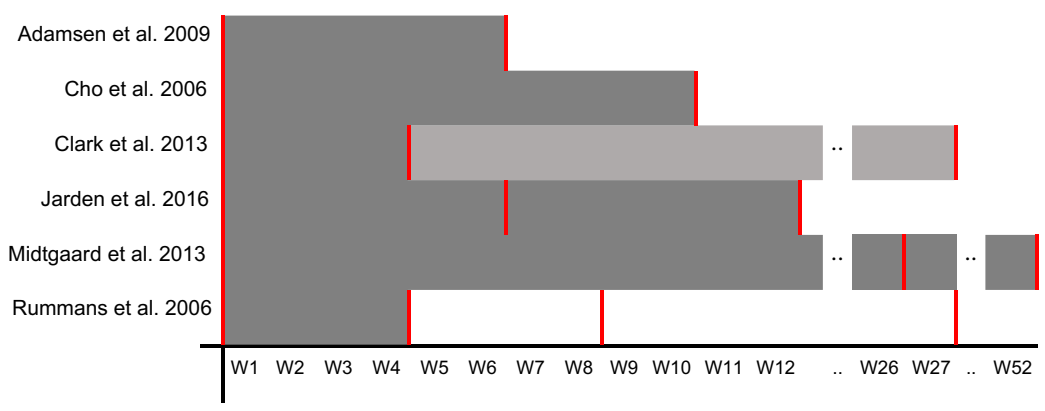

\section{b}

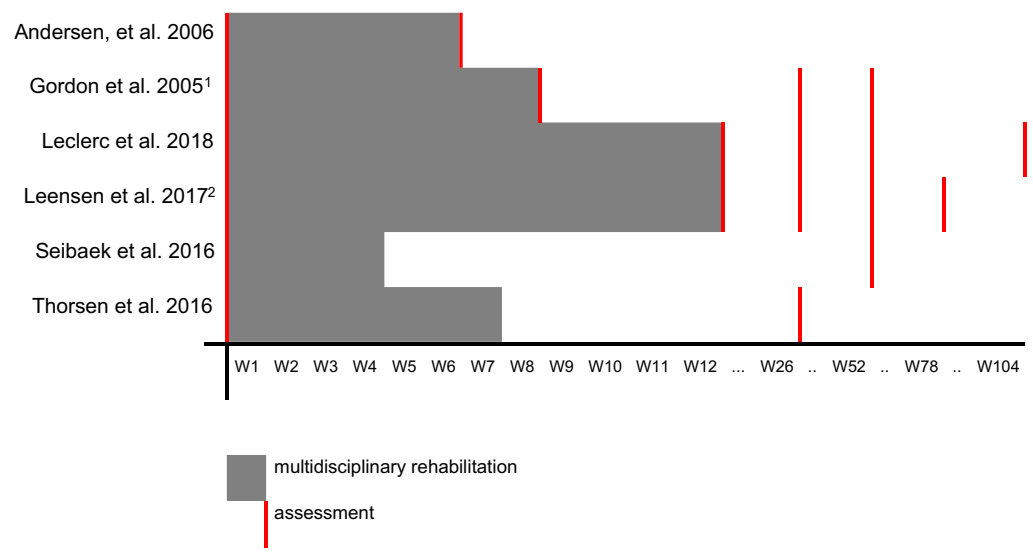

\section{Risk of Bias}

Two RCTs $[17,22]$ did not clearly mention the method of random sequence generation and were classified as being of unclear risk of bias. Four RCTs [16-18, 22] did not clearly describe the method of allocation concealment and thus were classified as being of unclear risk of bias. All RCTs were classified with a high risk of performance bias as it was not possible to blind the participants and personnel to the allocated interventions. Also, outcome assessments included patient self-reports, which were not blinded. Therefore, all studies were classified as being at a high risk of detection bias. All studies reported the numbers and reasons for missing data, and either stated that the drop-outs were equal in intervention and control group and/or performed an appropriate analysis to prove that the missing data had no impact on the results. Hence, all studies were classified as being at low risk of attrition bias. Study protocols of two RCTs were available [16, 17], and as all the prespecified primary and secondary outcomes have been reported in the publications, both studies were classified with low risk of reporting bias. However, for the rest of the RCTs, there was insufficient information to allow for any judgment other than 'unclear risk of bias'. Bias due to confounding was classified as being low in all RCTs except for the study of Clark et al. ( [20)], which was classified as unclear (Fig. $3 \mathrm{a}$ and b).

Overall, all before-after studies were assessed as being of high risk of bias in most categories. This is due to the study design and the nature of the interventions. Two before-after studies [23, 24] were controlled studies, which neither used randomization nor allocation concealment and were, therefore, rated as being of high risk of selection bias. The remaining before-after studies did not have a control group, which indicates a high risk for selection bias. As a result of the nature of the interventions and the study design in all before-after studies, it was not possible to blind the participants. Due to a high drop-out rate (around 30\%), four studies [19, 24, 25, 27] were assessed as being of high risk of attrition bias. Study protocols of before-after studies could not be detected, and thus were all classified as being of unclear risk of reporting bias. Four studies [19, 24, 25, 27] did not control for confounding and were, therefore, classified as being of high risk of confounding bias (Fig. $4 \mathrm{a}$ and b). 
Fig. 3 a Assessment of 'risk of bias' for the included RCTs $(N=$ 6). b 'Risk of bias' graph for RCTs: judgments about each risk of bias item presented as percentages across all included studies $(N=6)$

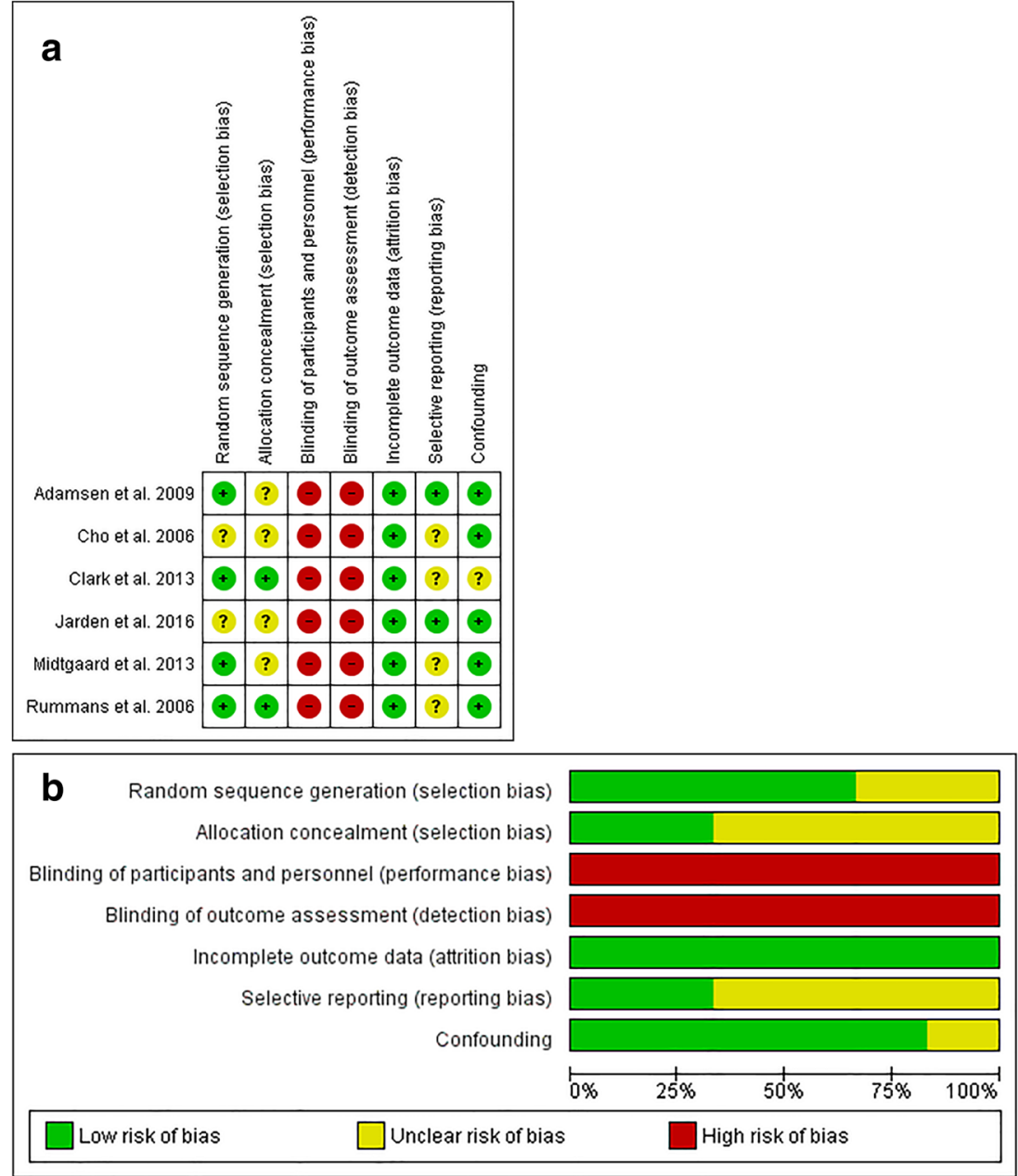

\section{Results of Individual Studies}

The significant and non-significant results of the measured outcomes of all RCTs and before-after studies are listed in Table 2. Regarding the physical status (i.e. objectively measured physical components and/or physical well-being) of cancer patients, each of the six RCTs observed statistically significant improvements in at least one of the outcomes measured. The most commonly reported significantly improved outcome was physical capacity/cardiorespiratory fitness, measured by VO2 max/peak exercise test [16-18]. Before-after studies came to similar conclusions, although fewer studies measured physical strength, but rather focused on self-reported physical well-being. Four studies observed statistically significant improvements in the physical status of cancer patients [19, 24-26]. Regarding the psychosocial status of cancer patients, five out of six RCTs observed statistically significant improvements of at least one outcome measure $[17,18,20-22]$. Four before-after studies showed that patients who underwent MOCR had improved their psychosocial status in a long-term view [19, 24-26]. Two before-after studies
$[25,26]$ were designed primarily to enhance return to work of cancer patients. Six months after the start of rehabilitation, $59 \%$ and $64 \%$ of cancer patients, respectively, had returned to work and in one study $83 \%$ of cancer patients had returned to work 18 months after the start of rehabilitation [25]. Improvements in the physical and/or psychosocial status of cancer patients have been detected for rehabilitation programmes that took place during the cancer treatment or up to 2 years after the cancer treatment. Improvements were also observed in patients with site-specific diagnoses and in cancer patients with different types of cancer.

\section{Discussion}

Our systematic review revealed positive effects of MOCR on the physical and/or psychosocial status of cancer patients. However, a variety of physical and psychosocial outcomes did not improve, or at least not significantly. Additionally, significant and non-significant rehabilitation effects were not consistent across studies. For example, several studies 
Fig. 4 a Assessment of 'risk of bias' for the included before-after studies $(N=6)$. b 'Risk of bias' graph for before-after studies: judgments about each risk of bias item presented as percentages across all included studies $(N=6)$
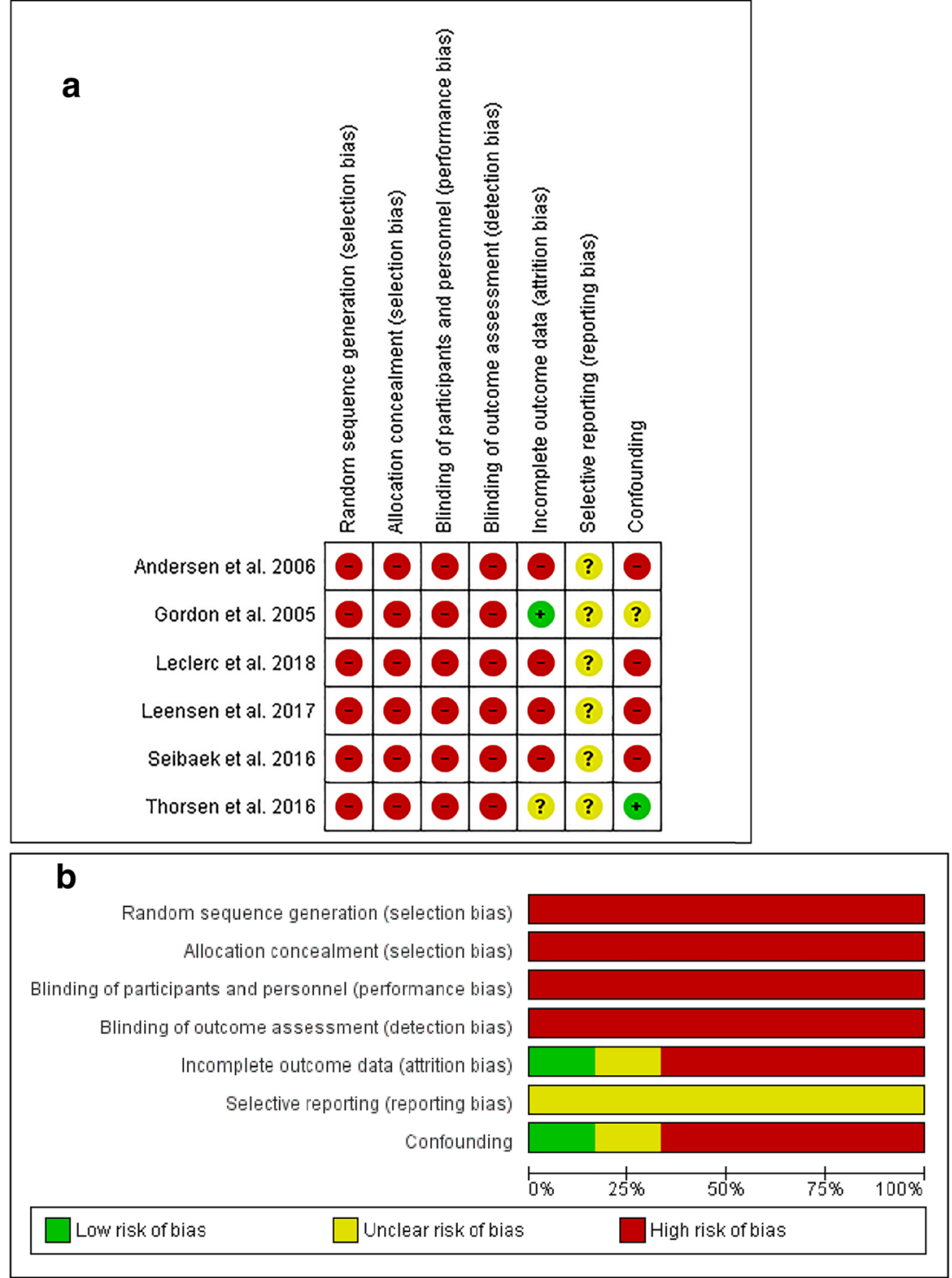

reported improvements in cardiovascular fitness, but the effects were observed through different metrics. Furthermore, there was insufficient evidence with respect to the long-term effects of MOCR on physical and/or mental health status of cancer patients as well as its effects on return to work status. Also, no evidence was observed that suggests that the effects of MOCR vary depending on the start of rehabilitation.

Our systematic review provides a comprehensive overview of the effects of MOCR on physical, psychosocial and return to work status. Similar results were obtained in one systematic review, but the review did not differentiate between inpatient and outpatient settings and focused only on multidimensional rehabilitation [13]. Another systematic review also observed that brief and focused multidimensional rehabilitation programmes are effective, but it also did not differentiate between inpatient and outpatient rehabilitation, and for several of the studies included, it was not clear how much time between the end of the primary active treatment (e.g. chemotherapy, radiotherapy or surgery) and the start of the rehabilitation had passed [14]. Therefore, with our search strategies focusing on MOCR, studies included in our review differed from those included in the previous reviews.

The absence of stratification by inpatient or outpatient settings in the two previously mentioned systematic reviews may be due to the fact that only few countries, in particular German-speaking countries (i.e. Germany, Austria and Switzerland), have a tradition of inpatient rehabilitation. However, as a result of political and structural changes, such as an aging population, an increasing number of cancer survivors and financial restrictions for inpatient care and outpatient rehabilitation become increasingly more important in these countries [28, 29]. One German epidemiological multicenter 
Table 2 Overview of results of individual studies in randomized controlled trials and before-after studies

\begin{tabular}{|c|c|c|c|}
\hline \multirow{2}{*}{$\begin{array}{l}\text { Author, year } \\
\text { of } \\
\text { publication }\end{array}$} & \multirow[t]{2}{*}{ Time point of assessment } & \multicolumn{2}{|c|}{ Results of the intervention group compared with control group } \\
\hline & & $\begin{array}{l}\text { Significant results, i.e. health } \\
\text { improvements }\end{array}$ & Non-significant results \\
\hline \multicolumn{4}{|c|}{ Randomized controlled trials } \\
\hline $\begin{array}{l}\text { Adamsen, } \\
2009\end{array}$ & $\begin{array}{l}\text { Week } 6 \text { after baseline } \\
\text { (post-rehabilitation) }\end{array}$ & $\begin{array}{l}\text {-Cardiorespiratory fitness (VO2max) } \\
\text {-Muscle strength (1RM) } \\
\text { EORTC QLQ-C30: } \\
\text {-Less Fatigue } \\
\text { MOS SF-36: } \\
\text {-Physical functioning } \\
\text { - Role physical } \\
\text { - Role emotional } \\
\text { - Mental health } \\
\text {-Vitality } \\
\text {-Mental component scale (summary } \\
\text { scale) } \\
\text {-Physical component scale (summary } \\
\text { scale) }\end{array}$ & $\begin{array}{l}\text {-Self-reported physical activity } \\
\text { EORTC QLQ-C30: } \\
\text { •QoL } \\
\text {-Role functioning } \\
\text {-Physical functioning } \\
\text { - Emotional functioning } \\
\text { - Cognitive functioning } \\
\text { - Social functioning } \\
\text { - Nausea and vomiting } \\
\text {-Pain } \\
\text {-Dyspnoea } \\
\text { - Insomnia } \\
\text {-Appetite loss } \\
\text {-Constipation } \\
\text {-Diarrhoea } \\
\text { - Financial difficulties } \\
\text { MOS SF-36: } \\
\text {-Bodily pain } \\
\text { - General health perceptions } \\
\text {-Social functioning }\end{array}$ \\
\hline Cho, 2006 & $\begin{array}{l}\text { Week } 10 \text { after baseline } \\
\quad \text { (post-rehabilitation) }\end{array}$ & $\begin{array}{l}\text {-Psychosocial adjustment } \\
\text {-Quality of life } \\
\text { Range of motion of the affected shoulder } \\
\text { joint: } \\
\text { •Extension } \\
\text {-Abduction } \\
\text {-External rotation } \\
\text {-Internal rotation } \\
\text {-Total score }\end{array}$ & $\begin{array}{l}\text { Range of motion of the affected shoulder joint: } \\
\text { •Flexion }\end{array}$ \\
\hline \multirow[t]{2}{*}{ Clark, 2013} & $\begin{array}{l}\text { Week } 4 \text { after baseline (post } \\
\text { intensive rehabilitation) }\end{array}$ & $\begin{array}{l}\text { FACT-G scales: } \\
\text { •Quality of life } \\
\text { •Physical well-being } \\
\text { •Functional well-being }\end{array}$ & $\begin{array}{l}\text { FACT-G scales: } \\
\text { •Social well-being } \\
\text { •Emotional well-being }\end{array}$ \\
\hline & $\begin{array}{l}\text { Week } 27 \text { after baseline (post } \\
\text { less-intensive rehabilitation) }\end{array}$ & & $\begin{array}{l}\text { FACT-G scales: } \\
\text { •Quality of life } \\
\text {-Physical well-being } \\
\text { •Functional well-being } \\
\text { •Social well-being } \\
\text { •Emotional well-being }\end{array}$ \\
\hline $\begin{array}{r}\text { Jarden, } \\
2016\end{array}$ & $\begin{array}{l}\text { Week } 6 \text { and week } 12 \text { after } \\
\text { baseline (post-rehabilitation) }\end{array}$ & 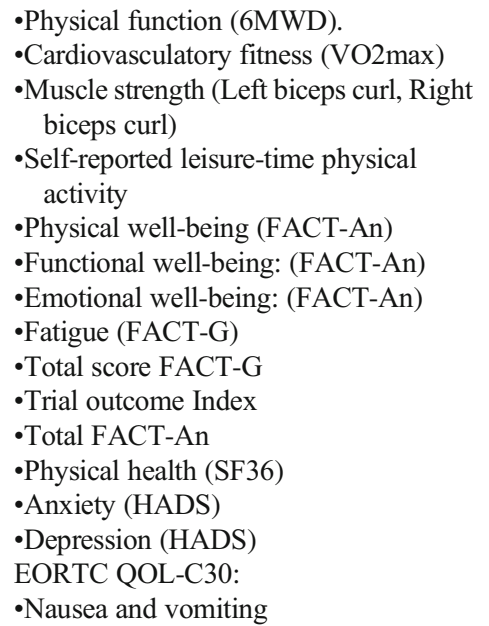 & $\begin{array}{l}\text {-Social well-being (FACT-An) } \\
\text {-Fatigue (EORTC QOL-C30) } \\
\text { Results that were not described in the article, but probably } \\
\text { are not significant: } \\
\text {-Subscale of FACT-An } \\
\text {-Subscales of FACT-G } \\
\text {-Subscales of EORTC QOL-C30 }\end{array}$ \\
\hline
\end{tabular}


Table 2 (continued)

Author, year Time point of assessment of

publication
Results of the intervention group compared with control group

Significant results, i.e. health Non-significant results improvements

- Global Health

-Emotional functioning

6 months after baseline (post-rehabilitation)

Midtgaard, 12 months after baseline 2013 (post-rehabilitation)
- Cardiorespiratory fitness (VO2peak absolute, $\mathrm{VO}_{2 \text { peak }}$ relative, peak power output, time to exhaustion)

- Upper and lower muscular strength (1RM)

-Cognitive functioning (EORTC QLQ-C30)

-Self-reported physical activity level -Cardiorespiratory fitness (VO2peak absolute, peak power output, time to exhaustion)

-Upper and lower muscular strength (1RM)

-Depression (HADS)

-Mental health (SF-36)
-Mental health
-Cardiorespiratory fitness (HR67watt)

EORTC QLQ-C30:

-QoL

-Physical functioning

-Role functioning

-Emotional functioning

-Social functioning

-Fatigue

-Nausea and vomiting

-Pain

-Dyspnoea

-Insomnia

-Appetite loss

- Constipation

- Diarrhea

- Financial difficulties

-Depression (HADS)

-Anxiety (HADS)

SF-36:

-Physical functioning

-Role physical

-Bodily pain

-General health perceptions

-Vitality

-Social functioning

-Role emotional

-Mental component scale (summary scale)

-Physical component scale (summary scale)

-Cardiorespiratory fitness $\left(\mathrm{VO}_{2 \text { peak }}\right.$ relative, HRpeak, HR67watt)

-Anxiety (HADS)

EORTC QLQ-C30:

-QoL

-Physical functioning

-Role functioning

-Emotional functioning

- Cognitive functioning

-Social functioning

-Fatigue

-Nausea and vomiting

-Pain

-Dyspnoea

-Insomnia

-Appetite loss

- Constipation

-Diarrhoea

-Financial difficulties

SF-36:

-PF

-Physical functioning

-Role physical

- Bodily pain

- General health perceptions

-Vitality

-Social functioning

-Role emotional 
Table 2 (continued)

Author, year Time point of assessment of

publication
Results of the intervention group compared with control group

Significant results, i.e. health Non-significant results improvements

Week 8 after baseline (post-rehabilitation)

Week 27 after baseline (post-rehabilitation)

Before-after studies

$\begin{array}{cc}\text { Andersen, } & \text { Daily self-assessment from } \\ 2006 & \begin{array}{l}\text { baseline until } 6 \text { weeks after } \\ \text { baseline (post-rehabilitation) }\end{array}\end{array}$

Gordon,

8 weeks after baseline

2005

(post-rehabilitation)

6 to 12 months after baseline (post-rehabilitation)
LASA:

-Overall quality of life

-Overall spiritual well-being

POMS:

Lower emotional distress:

-Tension/anxiety

•Confusion/bewilderment
-Myalgia

- Other pain

- Total pain

-Symptoms/side effects

DAART clinically but not statistically significant:

-Functional well-being,

-Arm function

-Global HRQoL

-Upper-body function

STRETCH:

-FACT-G

-FACT-B

$\cdot$ FACT-B+4
-Mental health

- Mental component scale (summary scale)

-Physical component scale (summary scale)

LASA:

-Cognitive

-Physical

-Emotional

-Social

-Pain frequency

-Pain severity

-Fatigue

-Social support

-Financial

-Legal

POMS:

-Total score

Symptom distress scale:

-Physical symptoms

Functional Assessment of Chronic Illness Therapy scale: -Spiritual well-being

-Lack of appetite

-Nausea

-Vomiting

- Diarrhoea

-Paraesthesia

-Constipation

-Physical fatigue

-Mental fatigue

-Treatment-related fatigue,

-Arthralgia

DAART:

-Physical well-being

-Functional well-being

-Breast cancer

-Arm morbidity

-FACT-G

-FACT-B

-FACT-B+4

-DASH

STRETCH:

-Physical well-being

-Functional well-being

-Breast cancer

-Arm morbidity

-DASH

Two intervention groups (early home based physiotherapy DAART and group-based exercise and psychosocial intervention STRETCH) compared with a control group and across time

Differences across time:

Differences across time:

-Physical well-being

- Breast cancer

-FACT-G
-Functional well-being

-Arm Morbidity

-FACT-B

•FACT-B+4 
Table 2 (continued)

Author, year Time point of assessment of

publication
Results of the intervention group compared with control group

Significant results, i.e. health Non-significant results improvements

-DASH

Differences across interventions:

-Physical well-being

-Functional well-being

-Breast cancer

-Arm morbidity

-FACT-G

-FACT-B

-FACT-B+4

-DASH

Leclerc, 3, 6, 12 and 24 months after 2018 baseline (post-rehabilitation)

Differences between experimental and control group:

EORTC QLQ-C30:

-Physical functioning

-Role functioning

-Emotional functioning

- Cognitive functioning

-Social functioning

-Fatigue

-Dyspnoea

-Financial difficulties

-QoL (EQ-5D)

Differences across time:

EORTC QLQ-C30:

-QoL

-Physical functioning

-Role functioning

-Emotional functioning

- Cognitive functioning

-Social functioning

-Fatigue

-Pain

-Dyspnea

-Insomnia

-Appetite loss

- Constipation

- Financial difficulties

-QoL (EQ-5D)

-Fatigue (FACIT)

-Anxiety state (STAI)

-Anxiety trait (STAI)

-Level of physical activity (FBACQ)

Interaction of group and time:

\section{EORTC QLQ-C30:}

-QoL

-Role functioning

-Physical functioning

-Emotional functioning

-Fatigue

-Pain

-Insomnia

-Diarrhea

-QoL (EQ-5D)

-Fatigue (FACIT)

-Anxiety state (STAI)

-Anxiety trate (STAI)
EORTC QLQ-C30:

-QoL

-Nausea and vomiting

-Pain

-Insomnia

-Appetite loss

-Constipation

-Diarrhoea

- Fatigue (FACIT)

-Anxiety state (STAI)

-Level of physical activity (FBACQ)

EORTC QLQ-C30:

-Nausea and vomiting

-Diarrhoea
(No time and group interaction measures, as interaction was not significant in model with interaction of EORTC QLQ-C30 scales: cognitive functioning, social functioning, nausea and vomiting, dyspnea, appetite loss, constipation, financial difficulties and for level of physical activity (FBACQ)) 
Table 2 (continued)

Author, year Time point of assessment of publication
Results of the intervention group compared with control group

Significant results, i.e. health Non-significant results improvements

After rehabilitation (only measures of muscle strength and cardiorespiratory fitness)

-VO2 peak $(\mathrm{ml} / \mathrm{min} / \mathrm{kg})$

-1RM leg press $(\mathrm{kg})$

-1RM deltoid pulley $(\mathrm{kg})$

-Maximal short exercise capacity

- (steep ramp test) (W)

Differences between baseline and 6 months:

-Rate of return to work RTW

-Perceived importance of work

-WLQ, time management

-WLQ, physical demands

-WLQ, production demands

-MFI, general fatigue

-MFI, physical fatigue

-MFI, reduced motivation

-MFI, reduced activity

-MFI, total score

-Physical activity

EORTEC QLQ-C30:

-Role functioning

-Cognitive functioning

-Fatigue

-Nausea

Differences between 6 and 18 months:

-Rate of return to work RTW

-Perceived importance of work

-Work ability (first item of WAI)

-Self efficacy regarding RTW

-MFI, general fatigue

-MFI, physical fatigue

-MFI, reduced motivation

-MFI, reduced activity

-MFI, mental fatigue

-MFI, total score

-Physical activity

EORTEC QLQ-C30:

-Physical functioning

-Role functioning

-Social functioning

- Fatigue

-Global health

SF36:

-Role physical

-Vitality

-Social dunctioning

-Role emotional

After rehabilitation (only measures of muscle strength and cardiorespiratory fitness)

-Maximal workload (W)

Differences between baseline and 6 months:

-Work ability (first item of WAI)

-Self efficacy regarding RTW

-WLQ, mental-interpersonal demands

-MFI, mental fatigue

EORTEC QLQ-C30:

-Physical functioning

-Emotional functioning

-Social functioning

-Pain

- Global health

Differences between 6 and 18 months:

-WLQ, time management

-WLQ, physical demands

-WLQ, mental-interpersonal demands

-WLQ, production demands

EORTEC QLQ-C30:

- Cognitive functioning

-Emotional functioning

-Nausea

-Pain
Seibaek, 12 months after baseline

2016 (post-rehabilitation)

Thorsen, 6 months after baseline 2016 (post-rehabilitation)
Patients who improved their work status at 6 months:

EORTEC QLQ-C30:

-QoL

-Physical functioning

-Role functioning

-Emotional functioning

- Cognitive functioning

-Social functioning
SF36:

-Physical functioning

-Bodily pain

- General health

-Mental health

-Sense of coherence

Patients who improved their work status at 6 months: EORTEC QLQ-C30:

-Constipation

-Diarrhoea

-Financial difficulties

Fatigue Questionnaire:

-Physical activity index

Patients who did not improve their work status at 6 months: 
Table 2 (continued)

\begin{tabular}{|c|c|c|c|}
\hline \multirow{3}{*}{$\begin{array}{l}\text { Author, year } \\
\text { of } \\
\text { publication }\end{array}$} & \multirow[t]{2}{*}{ Time point of assessment } & \multicolumn{2}{|c|}{ Results of the intervention group compared with control group } \\
\hline & & $\begin{array}{l}\text { Significant results, i.e. health } \\
\text { improvements }\end{array}$ & Non-significant results \\
\hline & & $\begin{array}{l}\text { - Fatigue } \\
\text { - Nausea and vomiting } \\
\text {-Pain } \\
\text { - Dyspnoea } \\
\text {-Insomnia } \\
\text { - Appetite loss } \\
\text { Fatigue Questionnaire: } \\
\text {-Physical fatigue } \\
\text { - Mental fatigue } \\
\text { - Total fatigue } \\
\text { Patients who did not improve their work } \\
\text { status at } 6 \text { months: } \\
\text { EORTEC QLQ-C30: } \\
\text { - QoL } \\
\text {-Physical functioning } \\
\text { - Role functioning } \\
\text {-Emotional functioning } \\
\text { - Fatigue } \\
\text {-Appetite loss } \\
\text {-Constipation } \\
\text {-Diarrhoea } \\
\text { - Financial difficulties } \\
\text { Fatigue Questionnaire: } \\
\text {-Physical fatigue } \\
\text {-Total fatigue } \\
\text {-Physical activity index }\end{array}$ & $\begin{array}{l}\text { EORTEC QLQ-C30: } \\
\text {-Cognitive functioning } \\
\text {-Social functioning } \\
\text {-Nausea and vomiting } \\
\text {-Pain } \\
\text {-Dyspnoea } \\
\text { - Insomnia } \\
\text { Fatigue Questionnaire: } \\
\text {-Mental fatigue }\end{array}$ \\
\hline
\end{tabular}

study with more than 4000 cancer patients from acute care hospitals, outpatient facilities and rehabilitation clinics compared QoL of patients with the general population. QoL was higher in the general population than in cancer patients, and QoL was higher in multidisciplinary rehabilitation and in an outpatient setting compared with the inpatient setting [30]. Besides for political and structural changes, MOCR meets the needs for improving QoL of each cancer patient considering the biopsychosocial model in understanding health. This model emphasizes that interconnections of biological, psychological and socio-environmental factors affect health, such that biopsychosocial care improves clinical outcomes, especially for chronic diseases [31]. Furthermore, rehabilitation that includes physical as well as psychosocial factors has been shown to be more effective on health, especially on pain management after cancer [32]. However, also intraindividual factors may play a role in rehabilitation outcomes [33].

As evidence is still limited, more studies are needed to strengthen the evidence of MOCR effects and to specify these effects on health to facilitate the development of evidence-based rehabilitation, national quality criteria and certified programmes. Nowadays, at least in Europe, rehabilitation is still not a well-established component of cancer control plans. The EUROCHIP-3 results showed that in 2011, 18 out of 25 European Union countries (72\%) reported cancer rehabilitation in their national cancer plans [34]. This same study revealed that only four European Union countries had cancer rehabilitation guidelines in 2011 and two were preparing guidelines. A preliminary work of the present review consisted of a targeted internet search in English, German, French, Italian, Norwegian, Swedish, Netherlands, Estonian, Finish and Chinese with respect to national guidelines for outpatient cancer rehabilitation. It was observed that the situation is even worse; out of 15 countries that provided information, only six countries were identified as having a national guidelines for outpatient cancer rehabilitation (Netherlands [35, 36], Sweden [37], Denmark [38-40], Germany [41, 42], Austria [43] and UK [44]).

\section{Strengths and Limitations}

The main strength of our review was the inclusion of both RCTs and before-after studies, which allowed for assessing a variety of outcomes, including return to work status, which was only assessed in before-after studies. However, only two before-after studies included a control group but had a high drop-out rate [23, 24]. Thus, improvements in physical and psychosocial status, as well as returning to work, could have 
occurred due to other reasons, e.g. passage of time, and not necessarily as a result of rehabilitation. Therefore, RCTs with higher methodological quality are needed to further evaluate the potential effects of cancer rehabilitation, especially in improving return to work status of cancer patients. A main limitation of the current systematic review was its narrative approach, which was not supplemented by meta-analyses. This was linked to the large heterogeneity and number of outcome measures, which made it difficult to compare the studies. Standards to assess rehabilitation effects and, hence, make assessments comparable across studies are urgently needed. Furthermore, the quality assessment showed that the overall methodology of the studies included was poor, partly due to the study design and partly due to methodological deficiencies of the studies.

Future randomized controlled trials should particularly analyze the long-term effects of MOCR and its effects in improving the return to work status of cancer patients. Due to the small number of studies with site-specific cancer, more research is needed regarding site-specific cancer rehabilitation programmes.

\section{Conclusion}

The findings of the systematic review indicate that MOCR can potentially improve cancer patients' physical and psychosocial status. But more research is needed, especially in regard to long-term outcomes, effectiveness on return to work status and on the associations depending on cancer type.

Funding Open access funding provided by University of Zurich. This study has been financed by Krebsliga Schweiz.

\section{Compliance with Ethical Standards}

Conflict of Interest The authors declare that they have no conflict of interest.

Human and Animal Rights and Informed Consent This article does not contain any studies with human or animal subjects performed by any of the authors.

Open Access This article is licensed under a Creative Commons Attribution 4.0 International License, which permits use, sharing, adaptation, distribution and reproduction in any medium or format, as long as you give appropriate credit to the original author(s) and the source, provide a link to the Creative Commons licence, and indicate if changes were made. The images or other third party material in this article are included in the article's Creative Commons licence, unless indicated otherwise in a credit line to the material. If material is not included in the article's Creative Commons licence and your intended use is not permitted by statutory regulation or exceeds the permitted use, you will need to obtain permission directly from the copyright holder. To view a copy of this licence, visit http://creativecommons.org/licenses/by/4.0/.

\section{References}

Papers of particular interest, published recently, have been highlighted as:

- Of importance

1. Phillips JL, Currow DC. Cancer as a chronic disease. Collegian. $2010 \mathrm{Jul} ; 17(2): 47-50$.

2. Stein KD, Syrjala KL, Andrykowski MA. Physical and psychological long-term and late effects of cancer. Cancer. 2008 Jun;112 (S11):2577-92.

3. Nas K, Yazmalar L, Şah V, Aydın A, Öneș K. Rehabilitation of spinal cord injuries. World J Orthop [Internet]. 2015;6(1):8-16. Available from: http://www.ncbi.nlm.nih.gov/pubmed/25621206. Accessed 4 Sep 2019.

4. Albrecht TA, Taylor AG. Physical activity in patients with advanced-stage cancer: a systematic review of the literature. Clin J Oncol Nurs [Internet]. 2012 1;16(3):293-300. Available from: $\mathrm{http} / /$ cjon.ons.org/cjon/16/3/physical-activity-patients-advancedstage-cancer-systematic-review-literature. Accessed 20 Nov 2019.

5. Speck RM, Courneya KS, Mâsse LC, Duval S, Schmitz KH. An update of controlled physical activity trials in cancer survivors: a systematic review and meta-analysis. J Cancer Surviv. 2010 Jun;4 (2):87-100.

6. Jacobsen PB, Donovan KA, Vadaparampil ST, Small BJ. Systematic review and meta-analysis of psychological and activity-based interventions for cancer-related fatigue. Health Psychol. 2007;26(6):660-7.

7. Sheard T, Maguire P. The effect of psychological interventions on anxiety and depression in cancer patients: results of two meta-analyses. Br J Cancer. 1999;80(11):1770-80.

8. de Boer AG, Taskila TK, Tamminga SJ, Frings-Dresen MH, Feuerstein M, Verbeek JH. Interventions to enhance return-towork for cancer patients. In: de Boer AG, editor. Cochrane Database of Systematic Reviews. Chichester: John Wiley \& Sons, Ltd; 2011. p. CD007569.

9. Pandey M, Thomas BC. Rehabilitation of cancer patients. J Postgrad Med. 2001;47(1):62-5.

10. Stubblefield MD, Hubbard G, Cheville A, Koch U, Schmitz KH, Dalton SO. Current perspectives and emerging issues on cancer rehabilitation. Cancer. 2013 Jun;119:2170-8.

11. Silver JK, Gilchrist LS. Cancer rehabilitation with a focus on evidence-based outpatient physical and occupational therapy interventions. Am J Phys Med Rehabil. 2011;90(SUPPL 5):S5-15.

12. Norrefalk JR. How do we define multidisciplinary rehabilitation? J Rehabil Med. 2003;35(2):100-1.

13. Mewes JC, Steuten LMG, Ijzerman MJ, Van Harten WH. Effectiveness of multidimensional cancer survivor rehabilitation and cost-effectiveness of cancer rehabilitation in general: a systematic review. Oncologist. 2012;17(12):1581-93. This is one of the two existing systematic reviews that examined the effects of multidimensional, but not necessarily multidisciplinary intervention.

14. Scott DA, Mills M, Black A, Cantwell M, Campbell A, Cardwell CR, et al. Multidimensional rehabilitation programmes for adult cancer survivors. Cochrane Database Syst Rev. 2013. This is one of the two existing systematic reviews that examined the effects of multidimensional and also multidisciplinary interventions.

15. Cochrane Handbook for Systematic Reviews of Interventions | Cochrane Training [Internet]. Available from: https://training. cochrane.org/handbook. Accessed 4 Mar 2019.

16. Adamsen L, Quist M, Andersen C, Møller T, Herrstedt J, Kronborg $\mathrm{D}$, et al. Effect of a multimodal high intensity exercise intervention 
in cancer patients undergoing chemotherapy: randomised controlled trial. BMJ. 2009;339:b3410.

17. Jarden M, Møller T, Christensen KB, Kjeldsen L, Birgens HS, Adamsen L. Multimodal intervention integrated into the clinical management of acute leukemia improves physical function and quality of life during consolidation chemotherapy: a randomized trial "PACE-AL". Haematologica. 2016;101(7):e316-9.

18. Midtgaard J, Christensen JF, Tolver A, Jones LW, Uth J, Rasmussen B, et al. Efficacy of multimodal exercise-based rehabilitation on physical activity, cardiorespiratory fitness, and patientreported outcomes in cancer survivors: a randomized, controlled trial. Ann Oncol. 2013;24(9):2267-73.

19. Seibaek L, Petersen K. Survivorship in Danish women surgically treated for gynecological cancer-The impact of postoperative rehabilitation. cns.sciedupress.com Clin Nurs Stud. 2016;4(4).

20. Clark MM, Rummans TA, Atherton PJ, Cheville AL, Johnson ME, Frost $\mathrm{MH}$, et al. Randomized controlled trial of maintaining quality of life during radiotherapy for advanced cancer. Cancer. 2013;119 (4):880-7.

21. Rummans TA, Clark MM, Sloan JA, Frost MH, Bostwick JM, Atherton PJ, et al. Impacting quality of life for patients with advanced cancer with a structured multidisciplinary intervention: a randomized controlled trial. J Clin Oncol. 2006;24(4):635-42.

22. Cho OH, Yoo YS, Kim NC. Efficacy of comprehensive group rehabilitation for women with early breast cancer in South Korea. Nurs Health Sci. 2006;8(3):140-6.

23. Gordon LG, Battistutta D, Scuffham P, Tweeddale M, Newman B. The impact of rehabilitation support services on health-related quality of life for women with breast cancer. Breast Cancer Res Treat. 2005;93(3):217-26.

24. Leclerc A-F, Slomian J, Jerusalem G, Coucke P, Bury T, Deflandre $\mathrm{D}$, et al. Exercise and education program after breast cancer: benefits on quality of life and symptoms at 3, 6, 12, and 24 months' follow-up. Clin Breast Cancer. 2018 May;18:e1189-204.

25. Leensen MCJ, Groeneveld IF, Heide I Van Der, Rejda T, Van Veldhoven PLJ, Van Berkel S, et al. Return to work of cancer patients after a multidisciplinary intervention including occupational counselling and physical exercise in cancer patients: a prospective study in the Netherlands. BMJ Open 2017;7(6).

26. Thorsen L, Dahl AA, Nystad R, Kiserud CE, Geirdal A, Smeland S. Baseline characteristics in female cancer patients with unimproved work status after an outpatient rehabilitation program and health changes during the intervention. Springerplus. 2016;5(1).

27. Andersen C, Adamsen L, Moeller T, Midtgaard J, Quist M, Tveteraas A, et al. The effect of a multidimensional exercise programme on symptoms and side-effects in cancer patients undergoing chemotherapy - the use of semi-structured diaries. Eur J Oncol Nurs. 2006;10(4):247-62.

28. Maehr B, Keilani M, Wiltschke C, Hassler M, Licht T, Marosi C, et al. Cancer rehabilitation in Austria-aspects of Physical Medicine and Rehabilitation. Wiener Medizinische Wochenschrift [Internet]. 2016 12;166(1-2):39-43. Available from: http://link. springer.com/10.1007/s10354-015-0414-1. Accessed 21 Nov 2019.

29. Manser T, Brösterhaus M, Hammer A. You can't improve what you don't measure: safety climate measures available in the Germanspeaking countries to support safety culture development in healthcare. Z Evid Fortbild Qual Gesundhwes [Internet]. 2016;114:58-71. Available from: http://www.ncbi.nlm.nih.gov/ pubmed/27566270. Accessed 19 Dec 2016

30. Hinz A, Weis J, Faller H, Brähler E, Härter M, Keller M, et al. Quality of life in cancer patients - a comparison of inpatient, outpatient, and rehabilitation settings. Support Care Cancer [Internet]. 2018;26(10):3533-41. Available from: http://link.springer.com/10. 1007/s00520-018-4211-4. Accessed 21 Nov 2019.
31. Kusnanto H, Agustian D, Hilmanto D. Biopsychosocial model of illnesses in primary care: a hermeneutic literature review. J Fam Med Prim care [Internet]. 2018;7(3):497-500. Available from: http://www.ncbi.nlm.nih.gov/pubmed/30112296. Accessed 16 Oct 2019.

32. Novy DM, Aigner CJ. The biopsychosocial model in cancer pain. Curr Opin Support Palliat Care [Internet]. 2014;8(2):117-23. Available from: http://www.ncbi.nlm.nih.gov/pubmed/24690764. Accessed 16 Oct 2019.

33. Tamagawa R, Garland S, Vaska M, Carlson LE. Who benefits from psychosocial interventions in oncology? A systematic review of psychological moderators of treatment outcome. J Behav Med [Internet]. 2012;35(6):658-73. Available from: http://www.ncbi. nlm.nih.gov/pubmed/22271329. Accessed 16 Oct 2019.

34. Niinepuu A Ülevaade vähihaigete rehabilitatsiooniprogrammidest Euroopa Liidus. [Internet]. University of Tartu, Tartu, Estonia; 2014. p. 1-74. Available from: https://dspace.ut.ee/handle/10062/ 43278. Accessed 19 Jan 2020.

35. Integraal Krankercentrum Nederland (IKNL). Cancer rehabilitation Landelijke richtlijn, Versie: 1.0 [Internet]. Nederland; 2011. Available from: https://www.oncoline.nl/index.php?language=en. Accessed 26 Mar 2018.

36. Integraal Krankercentrum Nederland (IKNL). Medisch specialistische revalidatie bij oncologie. Landelijke richtlijn, Versie: 1.0. [Internet]. 2018. Available from: https://www. oncoline.nl/medisch-specialistische-revalidatie-bij-oncologie. Accessed 19 Jun 2018

37. Regionala cancercentrum i samverkan. Nationellt vårdprogram cancerrehabilitering Version 2.0. [Internet]. 2019. Available from: https://www.cancercentrum.se/globalassets/vara-uppdrag/ rehabilitering-palliativ-vard/vardprogram/nationellt-vardprogramcancerrehabilitering.pdf. Accessed 19 Jan 2020.

38. Sundhedsstyrelsen. Forløbsprogram for rehabilitering og palliation i forbindelse med kræft - del af samlet forløbsprogram for kræft [Internet]. Sundhedsstyrelsen, København; 2018. Available from: https://www.sst.dk/ /media/ B0FD5078B1654B33A9E744CCBAE89022.ashx. Accessed 19 Jan 2020.

39. Kristiansen M, Adamsen L, Piil K, Halvorsen I, Nyholm N, Hendriksen C. A three-year national follow-up study on the development of community-level cancer rehabilitation in Denmark. Scand J Public Health. 2017;(September):1-8.

40. Kristiansen M, Adamsen L, Brinkmann FK, Jæ, Krasnik A, Hendriksen C. Need for strengthened focus on cancer rehabilitation in Danish municipalities. Dan Med J. 2015;62(4):A5045.

41. Kooperation die Bundesarbeitsgemeinschaft. Rahmenempfehlungen zur ambulanten onkologischen Rehabilitation. Bundesarbeitsgemeinschaft für Rehabilitation (BAR), Frankfurt am Main; 2004.

42. Gemeinsamer Bundesausschuss. Richtlinie des Gemeinsamen Bundesausschusses über Leistungen zur medizinischen Rehabilitation [Internet]. 2015. p. 1-12. Available from: https:// www.g-ba.de/downloads/62-492-1128/RL-Reha_2015-10-15_iK2016-04-01.pdf

43. Gyimesi M, Gerhard F, Sarah I, Elisabeth P, Andreas S, Sabine K, et al. Rehabilitationsplan 2016. Wien: Gesundeit Österreich; 2016.

44. Cancer Services Coordinating Group. National standards for rehabilitation of adult cancer patients. Welsh Assembly Government; 2010 .

Publisher's Note Springer Nature remains neutral with regard to jurisdictional claims in published maps and institutional affiliations. 